\title{
A late onset solitary mediastinal cystic lymphangioma in a 66-year-old woman who underwent kidney transplantation
}

\author{
Jung Mo Lee ${ }^{1}$, Sang Hoon Lee', Youngmok Park', Chi Young Kim¹, Eun Kyoung Goag', \\ Eun Hye Lee ${ }^{1}$, Ji Eun Park', Chang Young Lee ${ }^{2}$, Se Kyu Kim ${ }^{1}$ \\ ${ }^{I}$ Division of Pulmonology, Department of Internal Medicine, Institute of Chest Diseases; ${ }^{2}$ Thoracic and Cardiovascular Surgery, \\ Severance Hospital, Yonsei University College of Medicine, Seoul, Korea
}

Lymphangioma is a congenital abnormality of the lymphatic system detected primarily in early childhood. There are rare reports of mediastinal lymphangioma in older adults. We hereby report on a 66-year-old female patient who underwent kidney transplantation 20 years previously and who developed pathologically confirmed solitary mediastinal lymphangioma 1 year ago. Chest radiography showed a mediastinal nodule, which was not observed 2 year previously, therefore she was referred to the pulmonary division. She had no symptoms, and chest computed tomography demonstrated a $25-\mathrm{mm}$, well-defined, low-density nodule located at the anterior mediastinum. The size of the nodule had increased from $25 \mathrm{~mm}$ to $34 \mathrm{~mm} 1$ year later, and it was completely resected via video-assisted thoracic surgery. The histological diagnosis was cystic lymphangioma. Therefore, we recommend that clinicians consider cystic lymphangioma as a possible diagnosis even in older patients with a mediastinal cystic mass that shows progressive enlargement.

Keywords: Cystic lymphangioma; Mediastinum; Video-assisted thoracic surgery

\section{INTRODUCTION}

Cystic lymphangioma is a rare benign tumor. It is a congenital abnormality of the lymphatic system, detected primarily in early childhood [1]. Although this may occur in any part of the body, primarily in the head, neck, axilla, and abdomen, there are rare reports of mediastinal lymphangioma, particularly in older adults [2]. Occasionally, mediastinal cystic lymphangioma can grow slowly and cause symptoms. However, because of a lack of symptoms, the majority of cases are diagnosed incidentally. Surgical resection is the treatment of choice and allows for a definitive diagnosis based on histopathology. We hereby report on a 66-year-old female patient with pathologically confirmed late onset, slow grow-

Received: June 15, 2015, Revised: July 29, 2015,

Accepted: August 21, 2015

Corresponding Author: Se Kyu Kim, Division of Pulmonology, Department of Internal Medicine, Yonsei University College of Medicine, 50 Yonsei-ro, Seodaemun-gu, Seoul 03722, Korea

Tel: +82-2-2228-1954, Fax: +82-2-393-6884

E-mail: SEKYUKIM@yuhs.ac ing, solitary mediastinal lymphangioma.

\section{CASE}

A 66-year-old woman, who had undergone kidney transplantation surgery 20 years previously, was referred to the pulmonary division, because a chest radiograph incidentally showed a right upper mediastinal nodule. Her previous chest radiograph had not shown any abnormal findings (Fig. 1), and she did not complain of any respiratory symptoms such as cough, dyspnea, or chest pain. She had no history of any tumor, but had kidney transplantation, osteoporosis, hypercholesterolemia, and hypertension.

The routine laboratory tests were within the normal range, and the tests for autoimmune markers including fluorescent antinuclear antibody and anti-neutrophil cytoplasmic antibody were negative.

Contrast enhanced chest computed tomography (CT) demonstrated a $25-\mathrm{mm}$ sized, well-defined, non-enhancing, and lowdensity nodule located at the right upper anterior mediastinum. The nodule observed on the CT scan was initially 


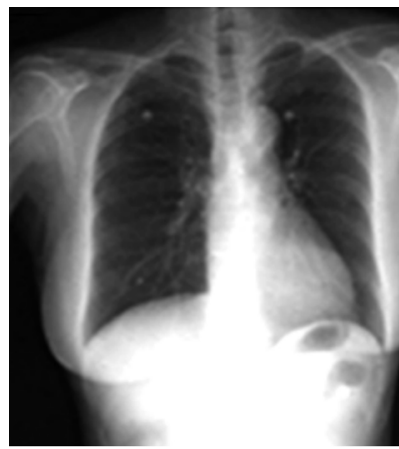

(A) 6 years ago

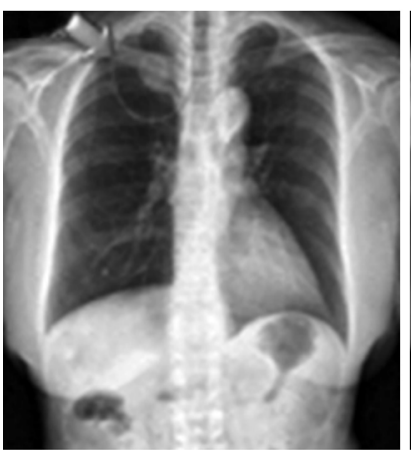

(C) 1 year ago

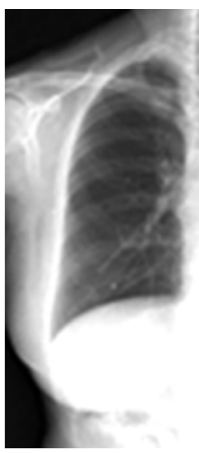

(B)

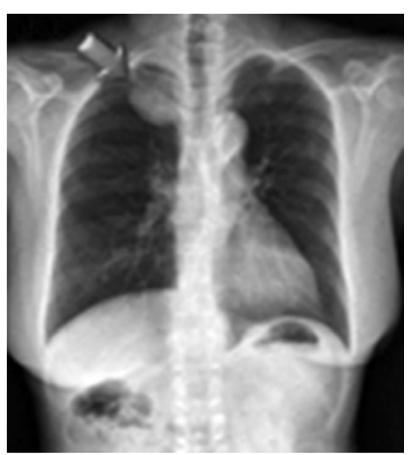

(D)

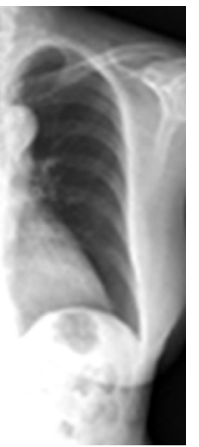

2 years ago

At operation

Fig. 1. Six years ago, there was no abnormal finding on chest X-ray. However, serial chest X-ray showed a slowly growing mass on the right upper lobe.

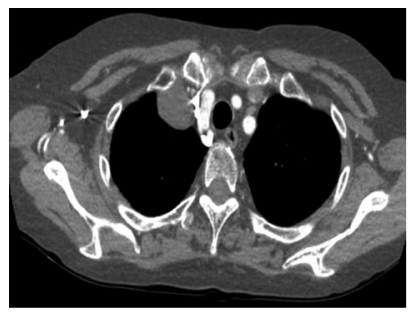

(A) 1 year ago

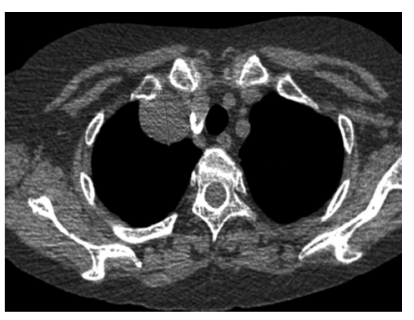

(B) At operation

Fig. 2. (A) Contrast chest computed tomography scan shows a non-enhancing $25 \mathrm{~mm}$ well-defined low density nodule at the right upper anterior mediastinum. (B) One year later, non-contrast follow-up chest CT scan shows a $34 \mathrm{~mm}$ nodule increasing in size.
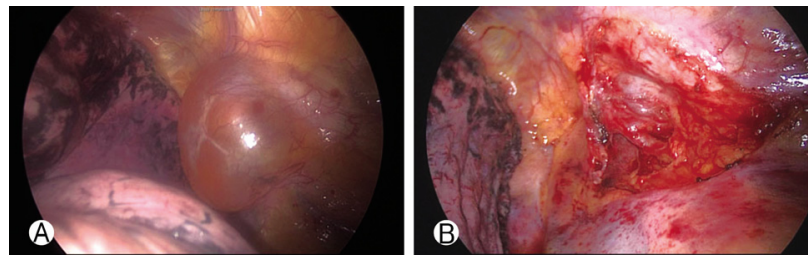

Fig. 3. (A) Video-associated thoracoscopic surgery (VATS) showed an approximately $3.5 \mathrm{~cm}$ sized cystic mass on the Rt. anterior mediastinum abutting to the phrenic nerve and internal mammary artery without invasion. (B) The cystic mass was completely removed using VATS.

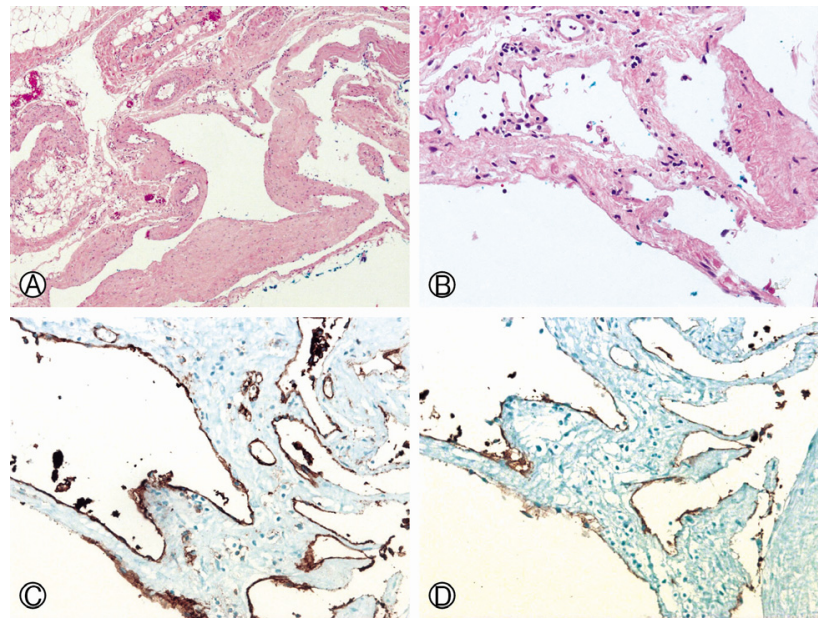

Fig. 4. (A) Low power magnification shows thin-walled cystic spaces $(H \& E$ stain, $\times 40)$. (B) The cystic spaces are lined by flattened endothelium (H\&E stain, $\times 200)$. (C, D) Lymphatic endothelium shows positivity for CD31 and D2-40 (immunohistochemical stain, $\times 200$ ).

suspected to be a benign cystic mass, such as a bronchogenic cyst, or a cystic change of a neurogenic tumor (Fig. 2A). Therefore, we decided to observe the patient for 1 year. A follow-up chest CT scan performed 1 year later, showed that the size of the nodule had increased from $25 \mathrm{~mm}$ to $34 \mathrm{~mm}$ in diameter (Fig. 2B).

Video-assisted thoracoscopic surgery (VATS) was performed for excision of the right anterior mediastinal lesion in order to exclude malignancy. The mediastinal cystic lesion measured $35 \mathrm{~mm}$ in diameter, abutting the phrenic nerve and internal mammary artery without invasion (Fig. 3A). During the operation, the cyst was partially ruptured and exudation of a clear yellowish fluid was observed. The cystic mass was completely removed (Fig. 3B). The excised mass measured $16 \times$ $11 \times 3 \mathrm{~mm}$, and showed a thin, smooth wall. Immunohistochemical staining showed positive staining for D2-40 and CD31, which supported the histological diagnosis of a cystic lymphangioma (Fig. 4).

The postoperative course was uneventful, and the patient completed 1-year of follow-up without delayed complications or any signs of recurrence (Fig. 5).

\section{DISCUSSION}

Cystic lymphangioma is a rare benign tumor, first described in 1843 by Wernher [3]. It is a congenital malforma- 
tion probably resulting from the sequestration of lymphatic tissue that does not communicate with the rest of the lymphovascular system [4].

Lymphangiomas are classified according to 3 groups: simple or capillary lymphangiomas, cavernous lymphangiomas, and cystic lymphangiomas. Capillary lymphangiomas consist of dilatation of capillary-sized lymphatic vessels connected to a normal lymphatic network. Cavernous lymphangiomas contain dilated lymphatic sinuses in an actively growing lymphoid stroma, which are also connected to normal lymphatics. Cystic lymphangiomas contain multiple large cyst-like spaces, lined by endothelial cells; the space may be empty or filled with clear proteinaceous or chylous fluid [5].

The most common site of a lymphangioma is head, neck, abdomen, and axilla; less than $1 \%$ of all lymphangiomas present as a solitary mediastinal mass [6]. More than $90 \%$ are discovered in individuals aged younger than 2 years.

The clinical presentation of mediastinal lymphangioma de-

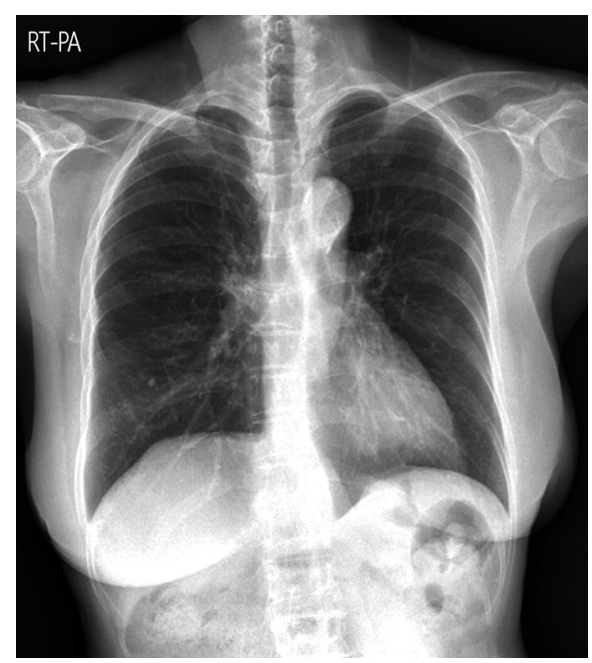

Fig. 5. Chest X-ray, taken 1 year after the operation, shows no abnormal finding without signs of recurrence. pends on the age of the patient and the extent of the tumor. Dyspnea is a predominant symptom in children. However, in adults, mediastinal lymphangioma is incidentally detected and is initially suspected to be a malignancy. Chest pain, dyspnea, and cough are noted only when the tumor grows to a large size [7]. Consistent with these general features, the patient described in the current study had no respiratory symptoms and was diagnosed on the basis of the radiographic abnormal findings during routine follow-up examination.

Radiologic studies such as chest radiography, chest CT, and magnetic resonance imaging (MRI) provide essential information. The site, anatomic links, and the infiltrating nature of lymphangiomas should be identified. On conventional chest radiograms, lymphangiomas are usually observed as sharply marginated, round or oval shaped tumors, with increased opacity. CT scans predominantly show them as cystic, clearly marginated, and thin-walled space-occupying lesions [8]. Although MRI is not performed routinely, it may be helpful, particularly in the differential diagnosis of other mediastinal masses. Despite the usefulness of CT, MRI, or both, differention between a bronchogenic cyst and a tumor is often impossible. Only complete excision of the cyst can establish a definitive pathologic diagnosis [9].

Although complete surgical resection is the traditional treatment of choice, there are controversies regarding its indications. In general, cystic mediastinal lymphangioma is rarely associated with malignancy and most patients are asymptomatic. Some authors support waiting or a conservative approach such as marsupialization, injection of sclerosing agents or steroids, diathermy, or radiotherapy; however, these are generally ineffective and have an increased risk of recurrence [10-13]. Therefore, surgery remains the preferred method for definitive diagnosis and treatment. Recently, less invasive methods such as VATS are gaining popularity for treatment

Table 1. Cases of mediastinal lymphangioma in Korea

\begin{tabular}{lcclcl}
\hline & Sex & Age & \multicolumn{1}{c}{ Symptom } & Pathologic diagnosis & Treatment \\
\hline Cho et al. [15] & M & 29 & Cough, sputum & Cavernous & Observation \\
Lee et al. [16] & F & 37 & Dyspnea on exertion & Cavernous & Surgical resection \\
Yeo et al. [17] & F & 52 & Asymptomatic & Cystic & Surgical resection \\
Kim et al. [18] & $\mathrm{M}$ & 77 & Cough & Cavernous & Observation \\
Kim et al. [19] & $\mathrm{M}$ & 30 & Asymptomatic & Cystic & Surgical resection \\
Kim et al. [19] & $\mathrm{M}$ & 31 & Asymptomatic & Cavernous & Surgical resection \\
Kim et al. [19] & $\mathrm{F}$ & 48 & Asymptomatic & Cavernous & Observation \\
\hline
\end{tabular}


of mediastinal lymphangioma [14].

Lymphatic abnormalities frequently mimic other pathologic processes, particularly neoplastic processes. Despite use of multiple imaging modalities including chest radiography, CT, and MRI, diagnosis of cystic lymphangioma is often difficult, and a definitive diagnosis of cystic lymphangioma can only be made by surgical resection and histopathological confirmation.

Cystic lymphangioma, a rare congenital anomaly of the lymphatic system, is usually detected within 2 years after birth, but an increase in the prevalence of late-onset mediastinal cystic lymphangioma has been observed, primarily in older adults. However, the reason why development of mediastinal cystic lymphangioma occurs in older age remains unclear. In Korea, 7 cases of solitary mediastinal lymphangioma have been published (Table 1), and patients were treated with surgical resection [15-19]. Three patients were under observation, and no significant change in size was observed during the follow-up period.

In our case, the patient regularly underwent chest radiography. Six years previously, her chest radiograph showed no abnormal findings. However, 1 year ago, a mediastinal cystic mass was detected incidentally and showed progressive enlargement during the 1-year follow-up period. Therefore, mediastinal cystic lymphangioma might develop secondary to a disorder, and it is not congenital; this characteristic should be elucidated in the future. However, in our patient, the cause of late-onset mediastinal cystic lymphangioma was unknown.

Therefore, we recommend that clinicians consider cystic lymphangioma as a possible diagnosis even in older patients with a mediastinal cystic mass that shows progressive enlargement.

\section{CONFLICTS OF INTEREST}

No potential conflict of interest relevant to this article was reported.

\section{REFERENCES}

1. Surlin V, Georgescu E, Dumitrescu C, Râmboiu S, Comănescu MV, Ghiluşi M. Retropancreatic cystic lymphangioma - considerations upon a case. Rom J Morphol Embryol 2011; 52(1 Suppl):493-6.

2. Brown LR, Reiman HM, Rosenow EC 3rd, Gloviczki PM, Divertie MB. Intrathoracic lymphangioma. Mayo Clin Proc 1986;61:882-92.

3. Zakaria RH, Barsoum NR, El-Basmy AA, El-Kaffas SH. Imaging of pericardial lymphangioma. Ann Pediatr Cardiol 2011; 4:65-7.

4. Oshikiri T, Morikawa T, Jinushi E, Kawakami Y, Katoh H. Five cases of the lymphangioma of the mediastinum in adult. Ann Thorac Cardiovasc Surg 2001;7:103-5.

5. Singh S, Baboo ML, Pathak IC. Cystic lymphangioma in children: report of 32 cases including lesions atrrare sites. Surgery 1971;69:947-51.

6. Bossert T, Gummert JF, Mohr FW. Giant cystic lymphangioma of the mediastinum. Eur J Cardiothorac Surg 2002;21:340.

7. Weissferdt A, Moran CA. Primary vascular tumors of the lungs: a review. Ann Diagn Pathol 2010;14:296-308.

8. Jeung MY, Gasser B, Gangi A, Bogorin A, Charneau D, Wihlm $\mathrm{JM}$, et al. Imaging of cystic masses of the mediastinum. Radiographics 2002;22(Spec No):S79-93.

9. Misthos P, Sepsas E, Kokotsakis I, Skottis I. Asymptomatic solitary mediastinal cystic lymphangioma: a rare entity. Asian Cardiovasc Thorac Ann 2006;14:476-8.

10. Ponn RB. Simple mediastinal cysts: resect them all? Chest 2003;124:4-6.

11. Okubo T, Shimada T, Narita Y, Okushiba T, Douke M, Takahashi $\mathrm{T}$, et al. A successful case report on intralesional OK-432 therapy for cystic mediastinal lymphangiomas. Kyobu Geka 1998;51:1017-21.

12. Westcott JL. Percutaneous needle aspiration of hilar and mediastinal masses. Radiology 1981;141:323-9.

13. Yildirim E, Dural K, Kaplan T, Sakinci U. Cystic lymphangioma: report of two atypical cases. Interact Cardiovasc Thorac Surg 2004;3:63-5.

14. Gürsoy S, Ozturk A, Ucvet A, Erbaycu AE. Benign primary cystic lesions of mediastinum in adult: the clinical spectrum and surgical treatment. Arch Bronconeumol 2009;45:371-5.

15. Cho SH, Han SK, Shim YS, Kim KY, Han YC, Kim JH, et al. A case of mediastinal lymphangioma. Korean J Med 1987; 33:821-6. Korean.

16. Lee HY, Park JK, Sim SB, Kim SW, Lee HK. Mediastinal lymphangioma - 1 case. Korean J Thorac Cardiovasc Surg 1992;25:1112-5. Korean.

17. Yeo DS, Lee DI, Lee KU, Kang DH, Park SK, Shin YK. A case of mediastinal cystic lymphangioma. Tuberc Respir Dis 1992;39:361-5. Korean.

18. Kim ST, Yong SJ, Lee WY, Kim MH, Shin KC, Kim SH, et al. A case of cavernous lymphangioma of the mediastinum in adult. Tuberc Respir Dis 2002;52:640-4. Korean.

19. Kim KC, Koh WJ, Kwon OJ, Lee BH, Hwang JH, Kang EH, et al. Mediastinal lymphangioma in adults: three case reports. Tuberc Respir Dis 2003;55:303-10. Korean. 